\title{
Metodologia para estimativa de demanda em uma rede cicloviária baseada no conceito de pontos de interesse
}

\author{
Methodology for demand prediction in a cycling network \\ based on the concept of points of interest
}

\author{
Guilherme Moyses Pfeffer ${ }^{1 *}$, Walber Paschoal da Silva ${ }^{1}$
}

\begin{abstract}
RESUMO
A alta taxa de ocupação do solo urbano, assim como eventuais restrições técnicas e financeiras, enfrentadas por muitas cidades brasileiras, podem gerar dificuldades para o planejamento adequado de sua rede cicloviária. O objetivo deste trabalho é desenvolver uma metodologia simplificada, com baixos custos de aplicação, capaz de auxiliar os técnicos durante o processo de planejamento de uma rede cicloviária, de forma confiável e acessível a todas as cidades, independentemente de seus recursos disponíveis. A metodologia apresenta as etapas para identificação dos pontos de interesse de viagens de bicicleta, definição do traçado das ciclovias e estimativa da demanda futura, e é testada através de um estudo de caso aplicado à Região Oceânica da cidade de Niterói, Rio de Janeiro, Brasil. Também é realizado um levantamento de tendências para medir possíveis mudanças nos hábitos de transportes locais e prever uma eventual demanda reprimida. Os resultados demonstram a eficácia e relevância da metodologia proposta, revelando um possível crescimento, até 2030 , de $102 \%$ no fluxo atual de ciclistas e de $12 \%$ na participação modal para viagens urbanas.
\end{abstract}

Palavras-chave: Infraestrutura cicloviária; Mobilidade urbana; Planejamento de transportes; Bicicletários; Pontos de interesse.

\begin{abstract}
The high occupancy rate of urban areas, as well as technical and financial constraints, faced by many Brazilian cities, can create difficulties for the proper planning of their cycling network. The objective of this paper is to develop a simplified methodology, with low costs of application, capable of helping technicians during the planning process of a cycling network, in a reliable and accessible way to all cities, regardless of their available resources. The methodology presents the steps for identifying points of interest for bicycle trips, defining cycle routes and estimating future demand, and is tested by a case study applied to the Oceanic Region of the city of Niterói, Rio de Janeiro, Brazil. It is also applied a trend survey to measure possible changes in local transport habits and predicting any repressed demand. The results demonstrate the effectiveness and relevance of the proposed methodology, revealing a possible growth, up to 2030 , of $102 \%$ in the current flow of cyclists and $12 \%$ in the modal share for urban trips.
\end{abstract}

Keywords: Cycling infrastructure; Urban mobility; Transport planning; Bike racks; Points of interest.

\footnotetext{
${ }^{1}$ Universidade Federal Fluminense. *E-mail: walberpaschoal@id.uff.br
} 


\section{INTRODUÇÃO}

O crescimento desordenado e a falta de ações efetivas, por parte das prefeituras, capazes de minimizar o problema e garantir a aplicação das diretrizes de desenvolvimento urbano, preconizadas pelos Planos Diretores, são fenômenos observados em muitas cidades brasileiras. Isso tem gerado graves problemas de mobilidade e um alto grau de dificuldade para o planejamento dos sistemas de transportes dessas cidades, tendo em vista essas incertezas e um predomínio do transporte motorizado, o que reconhecidamente não é a solução mais eficiente e sustentável. No Brasil, um estudo realizado pelo Ministério do Meio Ambiente revelou que no ano de 2012, os veículos de passeio foram responsáveis por $38 \%$ das emissões de $\mathrm{CO}_{2}$ (BRASIL, 2013).

Nesse cenário, a bicicleta surge como uma boa opção de mobilidade devido à ausência de emissões de $\mathrm{CO}_{2}$ e aos benefícios para a saúde. Por exemplo, um estudo realizado em Helsinque (CITY OF HELSINKI, 2015) revelou que para cada 1,00 euro investido na construção de uma nova ciclovia há um retorno de 7,80 euros. O uso da bicicleta está crescendo devido à busca por transportes favoráveis à saúde e ao meio ambiente. Segundo estudos realizados nos EUA e no Canadá, em 2012 foram registrados 865.000 usuários de bicicleta, o que significa um aumento de $11 \%$ em relação a 2009 (RELIANCE FOUNDRY, 2015).

O sistema de compartilhamento de bicicletas também tem apresentado um crescimento acelerado. Essa abordagem é mais uma alternativa para proporcionar ao cidadão uma oportunidade de repensar e mudar sua forma de se deslocar pela cidade. Em uma pesquisa realizada na China, Jiang et al. (2020) verificaram que, na reabertura das cidades após o pico da pandemia de COVID-19, a distância total percorrida pelas bicicletas compartilhadas sem estações, dependendo da cidade, substituíram entre $17 \%$ e $45 \%$ das viagens realizadas por veículos motorizados. Ainda segundo Jiang et al. (2020), nesse ritmo, a redução de emissões de $\mathrm{CO}_{2}$ gerada pelos sistemas de compartilhamento de bicicletas na China seria de 4,8 milhões de toneladas por ano.

O caso da Dinamarca merece destaque em virtude do seu crescimento acelerado e do seu atual domínio nos sistemas cicloviários. Os esforços da prefeitura resultaram na criação de novas ciclovias capazes de acomodar de $15 \%$ a $20 \%$ a mais de bicicletas, reduzindo em $10 \%$ o volume de carros nas ruas (DAC, 2014). 
Nesse contexto, verifica-se a importância dos sistemas cicloviários para as cidades, em virtude dos seus benefícios diretos sobre a mobilidade urbana, a saúde dos usuários desse modal, a redução de $\mathrm{CO}_{2}$ na atmosfera, e a melhoria na operação dos sistemas de transportes, com menos veículos motorizados circulando. Dessa maneira, um planejamento adequado dessas redes cicloviárias das cidades representa um fator de grande relevância no sentido de se obterem tais benefícios.

No entanto, a ampla maioria das cidades brasileiras não dispõe de conhecimento técnico especializado e/ou de recursos financeiros, suficientes para a realização de um planejamento de transportes convencional, a partir da aplicação dos métodos tradicionais e consolidados, os quais envolvem complexos estudos, simulações, cálculos, pesquisas e levantamentos de campo. Assim, um método mais simples e direto, baseado em levantamentos de campo com relativa facilidade de obtenção e estudos gráficos, se caracteriza como uma boa alternativa, pois, embora não tão preciso quanto os métodos tradicionais, pelo menos garante que fatores de maior influência sobre os deslocamentos de bicicleta sejam considerados.

\section{REFERENCIAL TEÓRICO}

Monteiro e Campos (2011) realizaram uma pesquisa cujo objetivo foi proporcionar uma melhor compreensão dos aspectos comportamentais dos usuários de duas estações de metrô na cidade do Rio de Janeiro, RJ, e sua integração com bicicletas e transporte a pé. A pesquisa foi realizada através de questionário socioeconômico e considerando fatores reativos à dificuldade dos deslocamentos. As conclusões permitiram medir o quanto o usuário está disposto a caminhar ou pedalar para acessar o metrô, e seu relacionamento com dados socioeconômicos e com as condições das vias.

Ainda se tratando de comportamento dos ciclistas e correlacionado com o caso do metrô, uma pesquisa elaborada por Paiva (2013), tratou de identificar fatores que interferem no uso da bicicleta, e sua integração com o modal de transporte metroviário, tendo como estudo de caso a estação de metrô Terminal Samambaia em Brasília, DF. Concomitantemente foi desenvolvido um método que buscava definir a demanda potencial e atual para estacionamento nessa estação, sua consequente atratividade para gerar a integração, e o interesse por embarcar com a bicicleta no vagão. Paiva (2013), 
então pode obter resultados interessantes, como os dois fatores mais importantes que induziram os usuários a não utilizarem a bicicleta, o roubo de bicicletas, e a falta de segurança imposta pelo tráfego de veículos nas vias. Como fatores que mais influem positivamente no uso da bicicleta, estão, a não agressão ao meio ambiente, e a redução dos gastos com transporte.

No trabalho elaborado por Campos e Cardoso (2016) é apresentada uma proposta metodológica para planejamento de um sistema cicloviário, com finalidade de servir de auxílio aos municípios. O trabalho se conduziu por duas vertentes: pesquisa junto a ciclistas, para identificação de rotas e motivos de escolha; e análise de parâmetros utilizados em outros métodos, que avaliam a infraestrutura cicloviária. Foi então definido e calculado um Índice de Adequação do Segmento para viagens por bicicleta, como forma de analisar a qualidade da rota escolhida e, dependendo do resultado, definir caminhos melhores.

\section{METODOLOGIA}

A metodologia proposta tem como base a identificação de regiões de planejamento e pontos de interesse, assim como a demanda por viagens de bicicleta, capazes de auxiliar os técnicos durante o planejamento do sistema cicloviário. A metodologia pretende ser simples, permitindo que até mesmo municípios com conhecimento técnico insuficiente na área, ou falta de recursos financeiros, sejam capazes de aplicá-la.

Assim, os pontos de interesse são identificados, e depois são estabelecidas as suas relações com as rotas. Complementarmente, é feita uma análise dos segmentos da estrada, de modo a proporcionar maior conforto e segurança para os ciclistas. No sentido de se garantir as bases para um dimensionamento de médio a longo prazo, a metodologia também propõe um procedimento para estimativa da demanda futura. Neste capítulo a metodologia proposta é descrita de maneira detalhada, e no sentido de simplificar a sua compreensão, o fluxograma da figura 1 apresenta a sequência das suas etapas.

Figura 1 - Fluxograma com as etapas da metodologia 


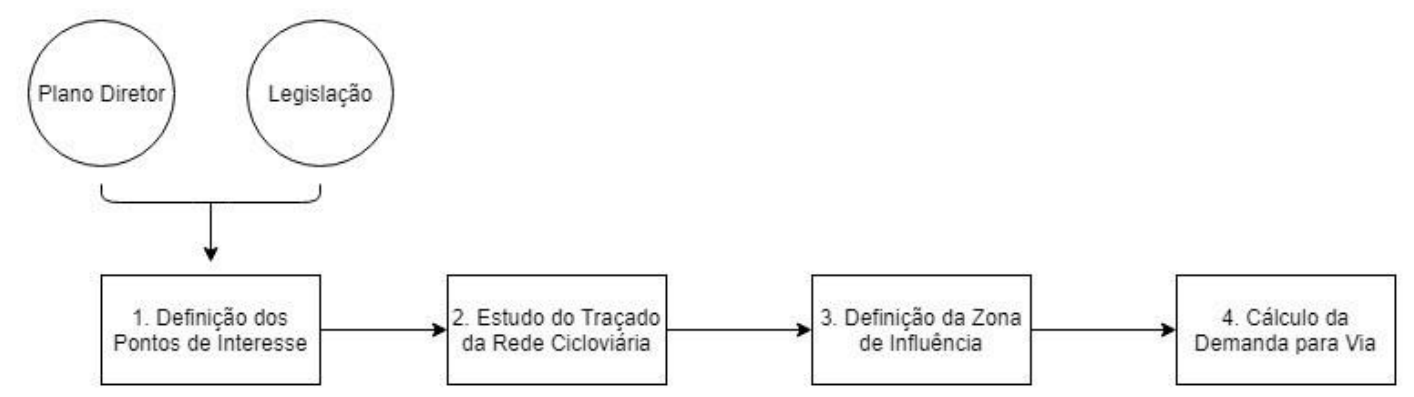

Fonte: Autores

\section{Identificação dos Pontos de Interesse ( $1^{\text {a }}$ Etapa)}

Os Pontos de Interesse aqui propostos representam os Polos Geradores de Viagem (PGV) ou Polos Geradores de Trafego, mas com características específicas para a geração de viagens por bicicleta. Podem ser definidos como locais ou instalações de distintas naturezas que desenvolvem atividades de porte e escala capazes de produzir um contingente significativo de viagens (PORTUGAL; GOLDNER, 2003).

O melhor balizador para um PGV é o Plano Diretor da cidade, uma vez que estabelece o funcionamento, crescimento e desenvolvimento de cada região da cidade, assim fornecendo um leque completo de informações e perspectivas. Outra forma de identificar um PGV é através de pesquisas de origem e destino. Contudo, tendo em vista os custos da elaboração de tal estudo, devemos assumir que nem todas as municipalidades terão como arcar com ele. Alguns exemplos de locais que se caracterizam como PGV são, pontos de integração entre modais, estações de metrô, estações de BRT, estações de barcas, shoppings, centros comerciais, parques, zona residenciais, etc.

\section{Estudo das rotas da rede cicloviária ( $2^{\mathrm{a}}$ Etapa)}

Para esta etapa, são utilizados os Pontos de Interesse definidos na etapa anterior, os quais servem como referências de deslocamento, ou seja, são usados como parâmetros de origem e destino. Dessa maneira, têm-se duas premissas básicas: a eficiência da bicicleta frente ao transporte motorizado, em relação a distância percorrida; a disposição do ciclista para percorrer essas distâncias. 
Segundo pesquisa de Monteiro e Campos (2011), ao analisar a estação de metrô do bairro da Pavuna, na cidade do Rio de Janeiro, foi constatado que cerca de $89 \%$ dos entrevistados que seguem de bicicleta para essa estação percorrem no mínimo 2,7 km, sendo que $52 \%$ se encontram na faixa entre $2,7 \mathrm{~km}$ e $5,40 \mathrm{~km}$. A flexibilidade gerada por uma rede de ciclovias bem estruturada pode gerar diversos ganhos para seus usuários. No deslocamento "porta-a-porta", nas grandes áreas urbanas, a bicicleta se mostra mais ágil do que carros, ônibus e pedestres em distâncias de até $5 \mathrm{~km}$ (BRASIL, 2007). Dessa forma, assume-se, aqui, que um Ponto de Interesse apresenta uma zona de influência com um alcance de $5 \mathrm{~km}$ de raio.

Caso ocorra sobreposição de rotas, deve-se adotar, para o planejamento, a rota com maior fluxo de bicicletas. Deve-se buscar sempre o caminho mínimo entre a origem e o destino, de forma a garantir um trajeto mais objetivo e rápido aos usuários da via. Os caminhos encontrados usualmente contam com dois sentidos de trânsito e são aqui denominados, Rotas. Os dois sentidos de tráfego são denominados A e B, assim gerando uma distinção entre diferentes sentidos de uma mesma rota.

\section{Definição da Zona de Influência ( $3^{\mathrm{a}}$ Etapa)}

Nesta etapa é adotado um modelo que leva em conta a distância $\left(\mathrm{d}_{\mathrm{PIi} \rightarrow \mathrm{PIj}}\right)$ entre os Pontos de Interesse $\mathrm{i}\left(\mathrm{PI}_{\mathrm{i}}\right)$ e $\mathrm{j}\left(\mathrm{PI}_{\mathrm{j}}\right)$, onde $\mathrm{d}_{\mathrm{PIi} \rightarrow \mathrm{PIj}} \leq 5 \mathrm{~km}$, com uma tolerância de $10 \%$, como sendo a base para o percurso entre os Pontos de Interesse. A Zona de Influência será definida a partir do percurso de PIi para PIj, conforme ilustra a figura 2.

Figura 2 - Definição da Zona de Influência

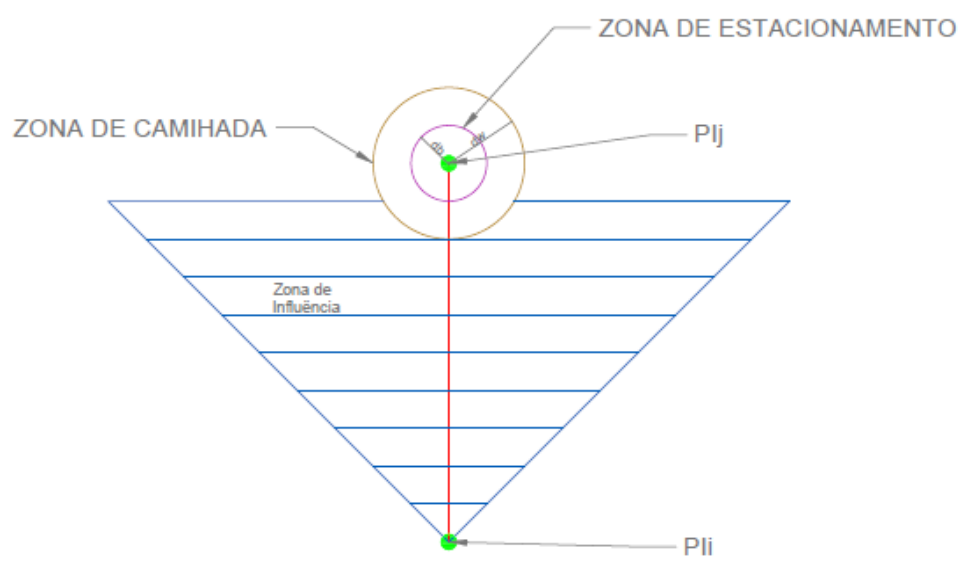

Fonte: Autores 
Com relação à distância em o pedestre geralmente prefere a caminhada frente aos outros modais de transportes, um estudo realizado na estação de metrô General Osório, no bairro de Ipanema, na cidade do Rio de Janeiro, a maior parcela adotou caminhadas de duração entre 5 a 10 minutos para chegar à estação, totalizando cerca de 550 a 1.100 m percorridos (MONTEIRO; CAMPOS, 2011). Assim, é proposta a variável Distância de Caminhada $\left(\mathrm{d}_{\mathrm{w}}\right)$, sendo $550 \mathrm{~m} \leq \mathrm{d}_{\mathrm{w}} \leq 1.100 \mathrm{~m}$.

O bicicletário, idealmente, deve se localizar o mais próximo possível do Ponto de Interesse final, neste caso o $\mathrm{PI}_{\mathrm{j}}$, sendo definida assim a variável Distância do Bicicletário $\left(d_{b}\right)$. Vale ressaltar que tanto db quanto $d_{w}$ são calculadas a partir do Ponto de Interesse 2. Contudo, muitas vezes a falta de espaço urbano impede o mesmo.

Conforme ilustrado na figura 2, é criado um triângulo que representa a Zona de Influência gerada pela ligação cicloviária de $\mathrm{PI}_{\mathrm{i}}$ até $\mathrm{PI}_{\mathrm{j}}$. $\mathrm{O}$ triângulo tem como objetivo idealizar uma linha ortogonal até a via, e da via até o db, onde serão estacionadas as bicicletas, que totalize 5,0 km de percurso até a região representada pela área de raio $\mathrm{d}_{\mathrm{b}}$. Deve ser subtraída da Zona de Influência da via, a região de raio $\mathrm{d}_{\mathrm{w}}$ a partir do $\mathrm{PI}_{\mathrm{j}}$ que representa a Zona de Caminhada, ou seja, a região onde a população possui a tendência maior de realizar o percurso a pé, evitando superdimensionamento.

A Tabela 1 exemplifica um segmento de via com $5.000 \mathrm{~m}$ de comprimento, estacas a cada $500 \mathrm{~m}$, e um ciclista se movimentando de um ponto dentro da Zona de Influência rumo ao $\mathrm{PI}_{\mathrm{j}}$, e como o entendimento da semelhança de triângulos ajuda a acharem as distâncias dentro do formato final.

Tabela 1 - Distância ortogonal à via na envoltória da Zona de Influência

\begin{tabular}{ccc}
\hline Estaca & $\begin{array}{c}\text { Distância } \\
(\mathrm{m})\end{array}$ & $\begin{array}{c}\text { Comprimento } \\
(\mathrm{m})\end{array}$ \\
\hline 0 & 0 & 5000 \\
1 & 500 & 4500 \\
2 & 1000 & 4000 \\
3 & 1500 & 3500 \\
4 & 2000 & 3000 \\
5 & 2500 & 2500 \\
6 & 3000 & 2000 \\
7 & 3500 & 1500 \\
8 & 4000 & 1000 \\
9 & 4500 & 500 \\
10 & 5000 & 0 \\
\hline
\end{tabular}

Fonte: Autores 
Em situações reais o alinhamento de uma via é composto por trechos em tangente e trechos em curva. Nesses casos trabalha-se com a distância total juntamente com um sistema de estaqueamento, onde a cada estaca será traçada uma ortogonal representando a distância do triângulo para aquele ponto, que pode ser obtida por uma simples semelhança de triângulos. Nos trechos em curva, o estaqueamento deve ser feito a cada $50 \mathrm{~m}$ ou $20 \mathrm{~m}$, de forma a ter uma envoltória mais precisa.

A figura 3 é um exemplo de uma situação onde a via possui $5.000 \mathrm{~m}$ de comprimento e foi estaqueada a cada $50 \mathrm{~m}$ com um ciclista se movimentando de um ponto dentro da Zona de Influência rumo ao PIj. A rota ciclável pode estar em regiões com barreiras geográficas, como lagoas e morros, impedindo que o indivíduo possa utilizá-la, mesmo estando dentro da Zona de Influência. Deve-se, então, dar um tratamento especial à envoltória, recortando-a nos limites dessas barreiras, conforme apresentado na figura 3 .

Figura 3 - Zona de Influência de uma via curvilínea com estaqueamento a cada 50m

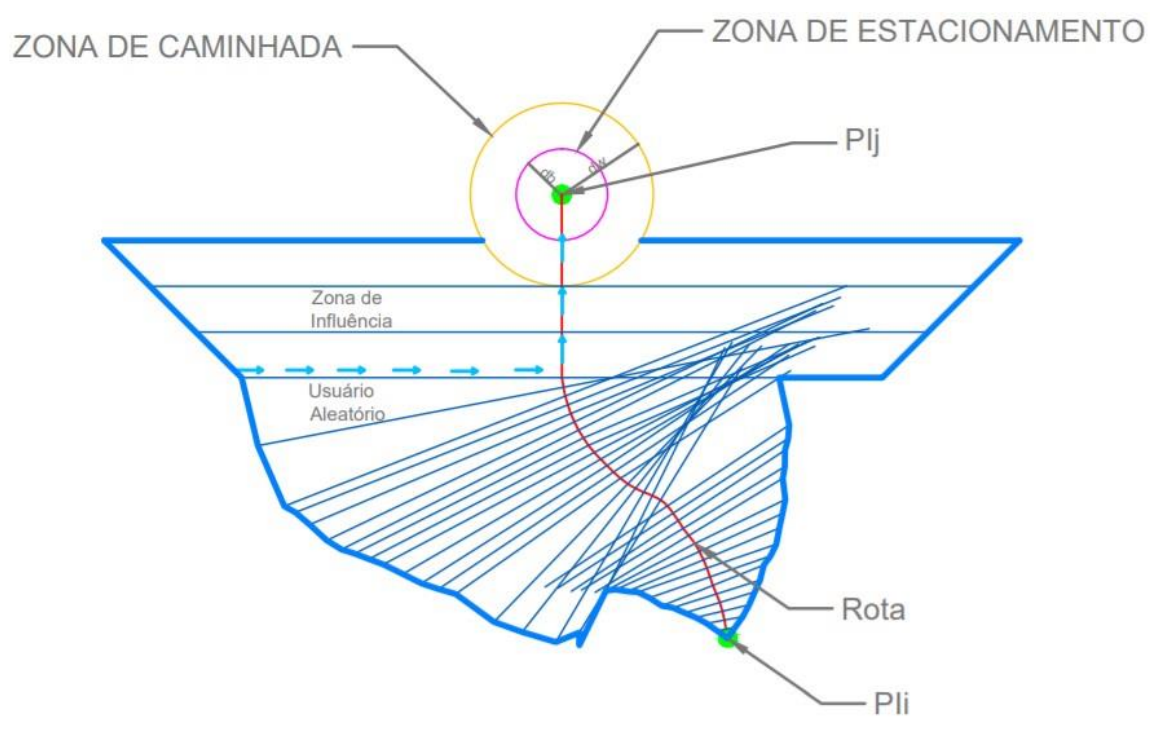

Fonte: Autores

\section{Cálculo da demanda para a via (4 $4^{\mathrm{a}}$ Etapa)}

Com base na envoltória que representa a Zona de Influência da ciclovia, desenvolvida na $3^{\text {a }}$ etapa, determina-se a população que nela reside. É necessária a determinação tanto da população, com base no censo mais recente à aplicação do método, como da estimativa da população futura para a área de estudo que pode ser obtida através de dados censitários e índices de crescimento populacional como os fornecidos pelo IBGE 
(Instituto Brasileiro de Geografia e Estatística). A taxa de crescimento populacional muitas vezes já é indicada diretamente pelas pesquisas. Caso isto não aconteça, pode-se calcular a mesma através da equação 1.

$$
T_{x}=\frac{N_{f}}{N}-1
$$

Onde: $\mathrm{T}_{\mathrm{x}}-$ taxa de crescimento populacio nal;

$\mathrm{N}_{\mathrm{f}}$ - tamanho da população futuro;

$\mathrm{N}$ - tamanho da população do censo mais próximo.

O agente tomador de decisão define a divisão modal atual e futura, junto com a definição do total do número de viagens. Existem dois tipos de pesquisas apropriadas aos objetivos desta pesquisa, as de origem e destino, e as pesquisas por questionários de preferências de tipo de transporte para locomoção, que podem auxiliar na obtenção destes dados. Caso existam dados suficientes, pode-se ainda trabalhar com métodos estatísticos de regressão linear. Contudo, visto que esta metodologia pretende contemplar cidades com menor grau de desenvolvimento, possivelmente não teriam o histórico de dados necessário.

Para este trabalho, foi adotada pesquisa direta com a população, por meio de questionário. Uma vantagem de utilizar modelos de questionário é o fato de contemplarem a demanda reprimida, ou seja, usuários que não utilizam esta opção devido à não existência de infraestrutura. Para a definição do tamanho da amostra deve-se adotar o mesmo método utilizado por de Paiva (2013), apresentado na equação 2.

$$
n_{o}=\frac{1}{E_{o}^{2}}
$$

Onde: $\mathrm{n}_{\mathrm{o}}$ - Primeira aproximação do tamanho da amostra;

$$
\mathrm{E}_{\mathrm{o}} \text { - Erro amostral tolerável. }
$$

Quando a população for mais de vinte vezes o tamanho de no, é recomendado adotar o valor calculado para no. Caso contrário, deve-se aplicar a equação 3. 


$$
n=\frac{N \times n_{o}}{N+n_{o}}
$$

Onde: $\mathrm{n}$ - tamanho da amostra.

A realização do cálculo da demanda está relacionada com o fluxo de bicicletas na via no horário de pico. Para a obtenção desse valor deve-se medir o fluxo a cada 15 minutos em cada segmento da via das $6 \mathrm{~h}$ às $21 \mathrm{~h}$. Com base nesses dados pode-se dar continuidade ao cálculo da demanda utilizando a equação 4 .

$$
V_{b f}=V_{b p} \times T_{x}\left(\frac{m_{f}}{m_{p}}\right)
$$

\section{ESTUDO DE CASO}

Para a aplicação da metodologia proposta foi escolhido o município de Niterói, no Estado do Rio de Janeiro. A área de estudo adotada foi a Região Oceânica. O trabalho é baseado num planejamento com horizonte no ano de 2030, contudo para o cálculo da adequação da segurança da via, foram usados parâmetros existentes atualmente. Os estacionamentos em geral possuem fácil capacidade expansão e a ociosidade produz efeito negativo sobre o mesmo, desta forma para esta parte foi feita uma análise considerando o cenário atual. A comparação com resultados obtidos através da metodologia permite avaliação de possíveis infraestruturas já existentes.

\section{Identificação dos Pontos de Interesse}

Nesta etapa, foram identificados os pontos de interesse na região de planejamento adotada por este trabalho. A figura 4 apresenta suas localidades geograficamente através da ferramenta Google Earth. 
Figura 4 - Pontos de Interesse e Rota do BHL georreferenciados pelo Google Earth

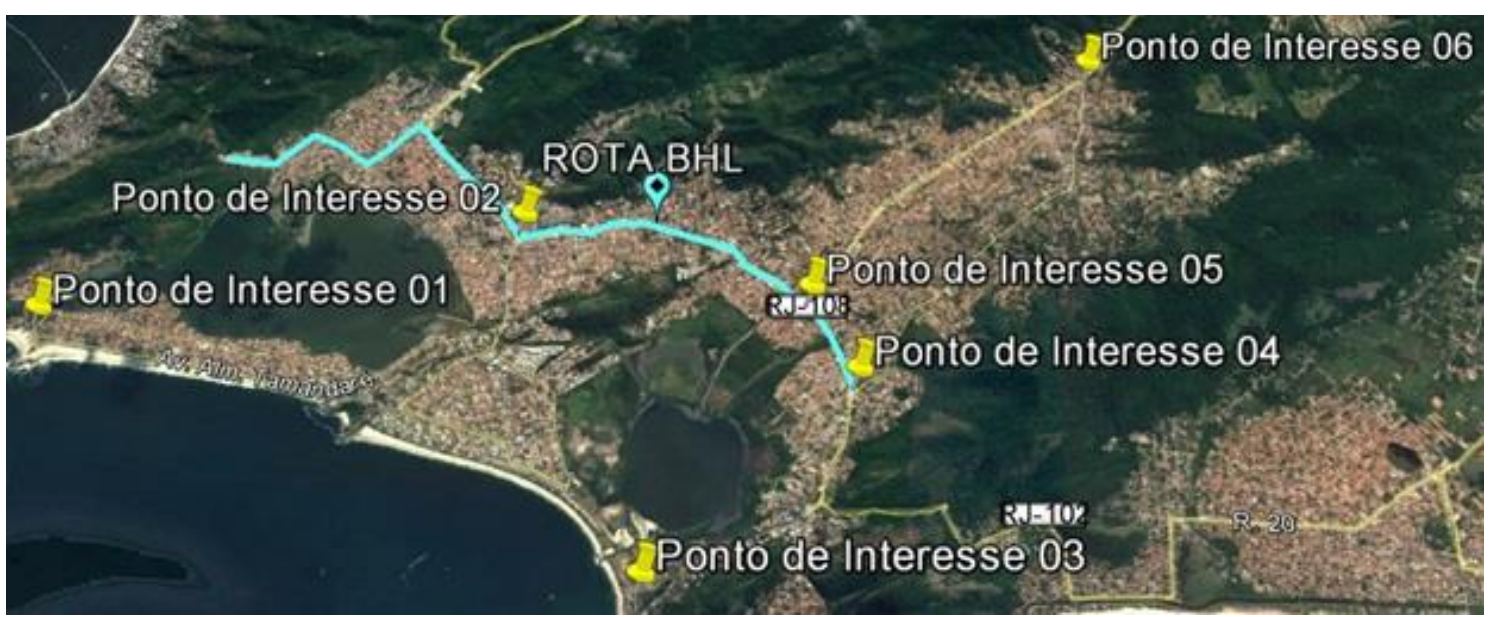

Fonte: Autores

- Ponto de Interesse 01 - Ponto final de diversas linhas de ônibus importantes na região;

- Ponto de Interesse 02 - Neste local fica o maior Shopping da Região Oceânica, um colégio municipal, e há a previsão de criação de uma estação do BHLS (Buses with a High Level of Service);

- Ponto de Interesse 03 - Ponto final de diversas linhas de ônibus importantes na região;

- Ponto de Interesse 04 - Ponto final do BHLS;

- Ponto de Interesse 05 - Polo comercial e residencial;

- Ponto de Interesse 06 - Entroncamento de duas vias arteriais de grande importância para a região, Av. Everton Xavier com a Estrada Engenho do Mato, e é um dos pontos limites da Região Oceânica.

\section{Estudo das rotas da rede cicloviária}

Com base na figura 4, foram calculadas as distâncias entre cada ponto através de simulações de rotas a pé, realizadas com o auxílio de ferramentas como o Google Maps e Sistemas de Informações Geográficas. A Tabela 2 expõe as possíveis rotas com base nas distâncias limites. 
Tabela 2 - Distância entre os Pontos de Interesse

\begin{tabular}{llll}
\hline De & Para & Distancia & Rota \\
\hline PI-01 & PI-02 & $5,2 \mathrm{~km}$ & 1 \\
PI-02 & PI-04 & $3,6 \mathrm{~km}$ & 2 \\
PI-03 & PI-05 & $3,7 \mathrm{~km}$ & 3 \\
PI-04 & PI-06 & $4,1 \mathrm{~km}$ & 4 \\
PI-05 & PI-06 & $3,7 \mathrm{~km}$ & 5 \\
\hline
\end{tabular}

Fonte: Autores

\section{Definição da Zona de Influência}

A partir desta etapa é analisada e dimensionada a Rota 1A, que representa o sentido PI-01 para PI-02, e a Rota 1B, que representa o sentido PI-02 para PI-01. A dimensão da mesma é de $5,2 \mathrm{~km}$, respeitando a margem de extrapolação de $10 \%$ dos 5 $\mathrm{km}$. Para a aplicação realizada foi adotado um estaqueamento de $50 \mathrm{~m}$. Vale ressaltar que foram adotados os valores $\mathrm{db}=100 \mathrm{~m}$ e $\mathrm{dw}=550 \mathrm{~m}$.

Tendo em vista que a localidade em que se encontra a Rota 1A possui diversas barreiras geográficas, a envoltória da zona de influência é tratada de forma a não considerar regiões que estão geograficamente isoladas, evitando superdimensionamento. Com isso, obtém-se os esquemas das figuras 5 e 6 , onde a figura 5 apresenta a envoltória simples, e a figura 6 , a envoltória com o tratamento geográfico.

Figura 5 - Envoltória de Influência da Rota 1A sem tratamento geográfico. Imagem obtida pelo Google Earth

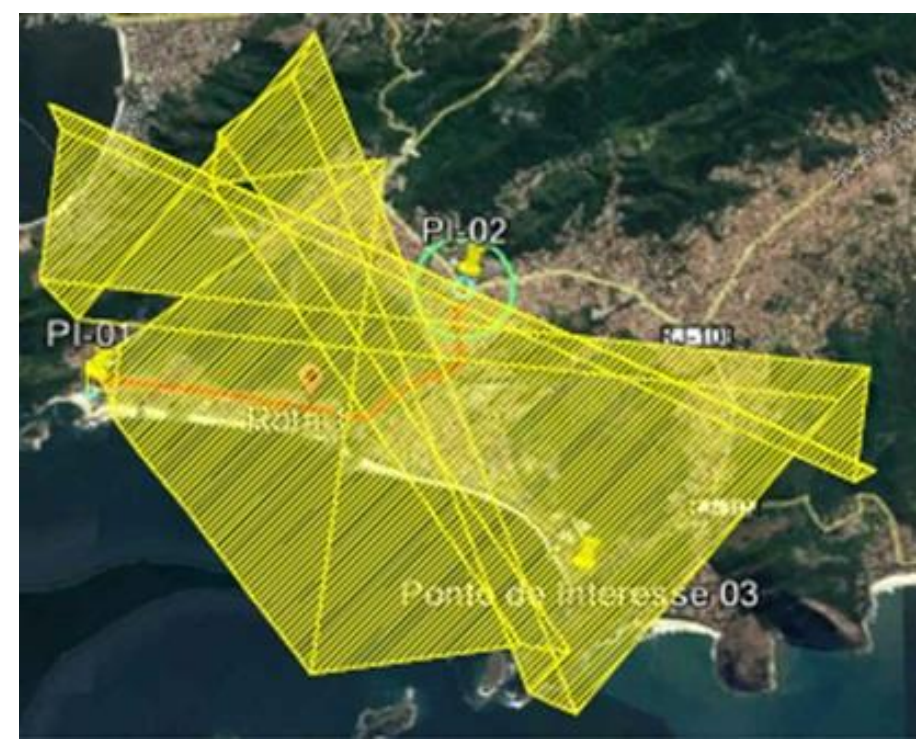

Fonte: Autores 
Figura 6 - Envoltória de Influência da Rota 1A com tratamento geográfico. Imagem obtida pelo Google Earth

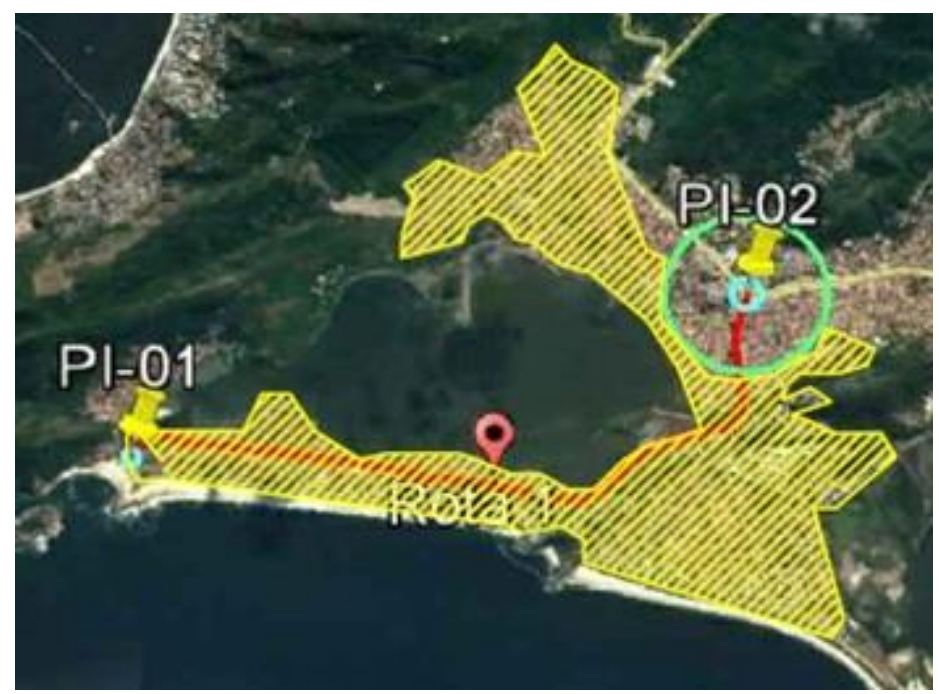

Fonte: Autores.

\section{Cálculo da demanda para a via}

A população do município de Niterói no censo de 2010 realizado pelo IBGE foi calculada em 487.562 pessoas (PREFEITURA DE NITERÓI, 2015). Contudo não foi obtida uma projeção a longo prazo da população da cidade de Niterói. Os sensos possuem geralmente intervalos periódicos e seguem alguns indicadores para projeções esporádicas, desta forma na ausência de dados se torna necessária a utilização de regressão linear, tendo em vista a simplicidade do cálculo.

Desta forma, o procedimento de cálculo da população futura para a cidade foi realizado através de regressão linear, utilizando-se de dados obtidos pelo IBGE (Instituto Brasileiro de Geografia e Estatística) totalizando 534.884 habitantes em 2013. A taxa de crescimento conforme a equação 1 , usando como valor presente a população do censo de 2010 de 487.562 habitantes, será de 9,71\%.

O tamanho da população foi obtido através do cálculo da área ocupada pela envoltória da zona de influência. Os dados para cálculo foram baseados em um estudo de renda e densidade populacional por setor censitário realizado pela Prefeitura Municipal de Niterói (2015). Considerando o caso mais desfavorável, o tamanho da população de estudo, para a definição do número de elementos amostrais, seria de 24.894 pessoas. Adotou-se então um erro amostral de $15 \%$ por ser um intervalo de incerteza ainda 
aceitável para uma fase de planejamento, e com custos mais baixos no levantamento de dados. Com base na equação 2, foi obtido o tamanho da amostra com 45 pessoas.

Os resultados da entrevista elucidaram um panorama de aumento na demanda pelo uso da bicicleta caso exista a infraestrutura adequada para utilização. Esse aumento tem impacto direto sobre o fluxo da infraestrutura cicloviária e afeta o uso dos demais modais de transportes. As modificações são apresentadas na tabela 3. O meio de transporte que mais sofreu redução percentualmente foi a combinação carro/moto, com uma redução de $6,81 \%$, e a bicicleta registrou um crescimento de $11,97 \%$, comprovando uma demanda inutilizada pela falta da infraestrutura adequada ao uso.

Tabela 3 - Divisão dos modais de transporte no presente e no futuro caso exista infraestrutura adequada

\begin{tabular}{lccr}
\hline Modal de Transporte & $\begin{array}{c}\text { Divisão de Modais } \\
\text { no presente }\end{array}$ & $\begin{array}{c}\text { Divisão de Modais } \\
\text { no Futuro }\end{array}$ & Variação \\
\hline Carro/Moto & $48,75 \%$ & $41,95 \%$ & $-6,81 \%$ \\
Taxi/Uber & $0,71 \%$ & $1,77 \%$ & $1,06 \%$ \\
Onibus & $26,69 \%$ & $23,19 \%$ & $-3,50 \%$ \\
Bicicleta & $12,99 \%$ & $24,96 \%$ & $11,97 \%$ \\
A pé & $10,85 \%$ & $11,68 \%$ & $0,83 \%$ \\
\hline
\end{tabular}

Fonte: Autores

A partir do resultado da divisão dos modais de transportes, obtido na etapa anterior, foram aplicados esses valores à equação 4 para o cálculo da demanda, para o ano de 2030, conforme mostra a tabela 4. Os valores de entrada foram:

- Taxa de crescimento (Tx): 9,71\%;

- Divisão de Modais no Presente (mp): 12,99\%;

- Divisão de Modais no Futuro (mf): $24,96 \%$.

Tabela 4 - Crescimento no fluxo de bicicletas na Rota 1A

\begin{tabular}{ccc}
\hline Segmento & $\begin{array}{c}\text { Fluxo no Presente } \\
\text { (bicicletas/h) }\end{array}$ & $\begin{array}{c}\text { Fluxo no Futuro } \\
\text { (bicicletas/h) }\end{array}$ \\
\hline 1 & 76 & 160 \\
2 & 100 & 211 \\
3 & 104 & 219 \\
4 & 116 & 245 \\
5 & 140 & 295 \\
\hline
\end{tabular}

Fonte: Autores 


\section{CONCLUSÕES}

Tendo em vista as vantagens do uso da bicicleta como modal de transporte apresentadas, este trabalho teve como objetivo desenvolver e testar uma metodologia capaz de auxiliar os tomadores de decisão durante o processo de planejamento de uma rede cicloviária. Os resultados revelaram que metodologia proposta se caracteriza por ser simples e direta, a partir de uma sequência lógica de procedimentos básicos e de relativa facilidade de obtenção, quando comparada aos métodos convencionais de planejamento de transportes. Portanto, embora também possa ser aplicada por cidades desenvolvidas, tem o seu foco voltado para as cidades menos desenvolvidas e com restrições de recursos financeiros e/ou de mão-de-obra técnica especializada.

O conceito dos Pontos de Interesse é de fundamental relevância para definir uma rede objetiva, gerando acessos mais curtos aos destinos, algo buscado pelos ciclistas (CAMPOS; CARDOSO, 2016). O tratamento geográfico da envoltória de influência possibilita a exclusão de áreas que seriam fisicamente mais distantes da via ou que não teriam conexões viárias adequadas dentro dos parâmetros estabelecidos, dessa forma balizando melhor a demanda.

Complementarmente, a boa compreensão da mobilidade da população local também depende de uma pesquisa de origem e destino (O/D), dando maior poder ao tomador de decisão. Contudo, levantamentos de O/D são onerosos e demandam conhecimento técnico especializado, inviabilizando sua aplicação para determinadas cidades. Dessa forma, o estudo recomenda que, quando possível, a pesquisa de O/D seja realizada, porém fornece ferramentas para auxiliar o tomador de decisão a planejar mesmo sem essa informação.

A aplicação do questionário, por meio de uma pesquisa de campo, teve fundamental importância para o melhor entendimento da dinâmica de transportes, por modal, da população inserida na envoltória de influência. Outro ponto positivo da pesquisa de campo foi criar uma percepção maior da demanda reprimida, gerada pela falta de infraestrutura adequada para os ciclistas, de forma a planejar evitando possível subdimensionamento. Os resultados apontaram um crescimento potencial de $11,97 \%$ do uso da bicicleta dentro da matriz de modais de transportes para a região estudada, 
reduzindo em quase 7\% a parcela ocupada pelos veículos motores do grupo carros e motos.

Tomando como base a taxa de crescimento populacional, o trabalho apresentou um método capaz de gerar um horizonte populacional de possíveis ciclistas para adequação do planejamento de médio a longo prazo, assim como medir a demanda reprimida, conforme apresentado no gráfico da figura 7. Os resultados indicaram um crescimento do fluxo de potenciais ciclistas de $102 \%$ até o ano de 2030 , alcançando uma divisão modal de quase 30\%, valor usual em cidades consideradas amigáveis para o uso da bicicleta.

Figura 7 - Comparação do fluxo de ciclistas no presente, no ano base de 2017, e o fluxo de ciclistas no futuro, no ano de 2030, por segmento na Rota $1 \mathrm{~A}$

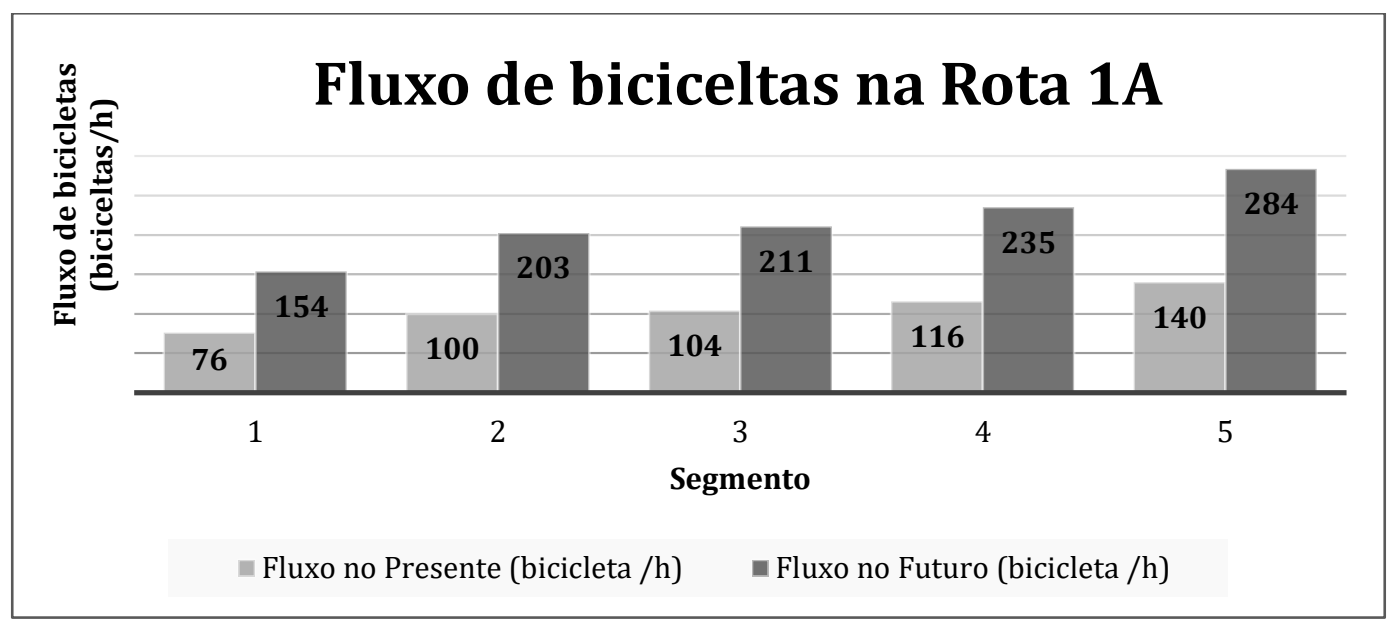

Fonte: Autores

A realização de um estudo de caso elucidou questões sobre a segurança e a operação da rede cicloviária proposta. O resultado final mostrou que todos os segmentos se encaixaram nos limites do Índice Geral de Adequação ao Segmento, ou seja, todos os segmentos tiveram valores maiores do que 1 , indicando a viabilidade desse planejamento.

Para assegurar a eficiência de uma rede cicloviária, bem como um crescimento ordenado e sustentável na demanda desse modal de transporte, além de um adequado planejamento, considerando as questões técnicas tratadas na metodologia proposta, também deve-se promover um acompanhamento constante de sua operação. Esse acompanhamento deve ser realizado por meio de fiscalização, de campanhas educativas, no sentido de garantir o respeito às sinalizações de trânsito e às leis relativas ao uso da bicicleta, e da avaliação regular do desempenho dessa rede. 
Dessa maneira, uma recomendação para futuros estudos que venham a contribuir para a evolução desta linha de pesquisa, seria a criação de métricas capazes de permitir uma avaliação eficaz do desempenho de uma rede cicloviária, assim como a adoção de políticas públicas capazes de potencializar a demanda pelo uso dessa rede cicloviária.

\section{REFERÊNCIAS}

BRASIL. Ministério das Cidades. Programa Bicicleta Brasil: plano de mobilidade por bicicleta nas cidades. Brasília, DF, 2007. Disponível em:

$<$ https://www.cidades.gov.br/images/stories/ArquivosSNPU/Biblioteca/PlanelamentoUr bano/PlanoDiretorParticipativoSNPU2006.pdf>. Acesso em: 16 fev. 2017.

BRASIL. Ministério do Meio Ambiente. Inventário Nacional de Emissões

Atmosféricas por Veículos Automotores Rodoviários. Brasília, DF, 2013. Disponível em:

<http://www.mma.gov.br/images/arquivo/80060/Inventario_de_Emissoes_por_Veiculos _Rodoviarios_2013.pdf>. Acesso em: 03 fev. 2017.

CARDOSO, Pablo de Barros; CAMPOS, Vânia Barcellos Gouvêa Campos.

Metodologia para planejamento de um sistema cicloviário. Transportes, v. 24, n.4, p. 39-48, 2016. Disponível em:

<https://www.revistatransportes.org.br/anpet/article/view/1158>. Acesso: 27/04/2017.

CRUZ, William. Por que 1,5m ao ultrapassar ciclista? Tem espaço pra isso? VA DE BIKE. 16 jul. 2015. Disponível em: < http://vadebike.org/2011/07/por-que-15m-aoultrapassar-ciclista-tem-espaco-pra-isso/>. Acesso em: 10 jun. 2017.

CTB (2008). Código de Trânsito Brasileiro, instituído pela lei nº 9.503, de 23/09/97. Brasília: DENATRAN. Disponível em <http://www.planalto.gov.br/ccivil_03/leis/L9503Compilado.htm>. Acesso em: $17 \mathrm{fev}$. 2017.

DANIS ARCHITECTURE CENTER. Copenhagen: the world's best city for cyclist. DAC\&Cities, 21 jan. 2014. Disponível em: < http://www.dac.dk/en/daccities/sustainable-cities/all-cases/transport/copenhagen-the-worlds-best-city-forcyclists/>. Acesso em: 11 abr. 2017.

DE PAIVA, Mariana. Fatores que influenciam no usa da bicicleta de forma integrada com o metrô. Brasília, DF, 2013.206 f. (Tese Doutorado em Transportes) Departamento de Engenharia Civil e Ambiental, Faculdade de Tecnologia, Universidade de Brasília, Brasília, 2013. Disponível em: <http://repositorio.unb.br/bitstream/10482/13266/1/2013_MarianadePaiva.pdf>. Acesso em: 09 nov. 2016.

IBGE - INSTITUTO BRASILEIRO DE GEOGRAFIA E ESTATÍSTICA. Panorama. Selecionado estado Rio de Janeiro, cidade Niterói. Disponível em: < https://cidades.ibge.gov.br/v4/brasil/rj/niteroi/panorama>. Acesso em: 10 jun. 2017. 
IBGE - INSTITUTO BRASILEIRO DE GEOGRAFIA E ESTATÍSTICA.

Infográficos: evolução populacional e pirâmide etária. Selecionado estado Rio de Janeiro, cidade Niterói. Disponível em:

http://www.cidades.ibge.gov.br/painel/populacao.php?lang=\&codmun=330330\&search $=\% 7$ Cniteroi $>$. Acesso em 10 ago. 2017;

JIANG, H.; SONG, S.; LU, L. Bicicletas compartilhadas sem estações podem criar uma mobilidade saudável e resiliente. World Resources Institute Brasil. 2020.

Disponível em: <https://wribrasil.org.br/pt/blog/cidades/bicicletas-compartilhadas-semestacoes-podem-criar-uma-mobilidade-saudavel-e-resiliente>. Acesso em: 09 dez. 2020.

MONTEIRO, Fernanda Borges; CAMPOS, Vânia Barcellos Gouvêa. Analisando viagens a pé e por bicicletas na integração com transporte de massa. Instituto Militar de Engenharia, Rio de janeiro, RJ. p. 6. 2011. Disponível em:

$<$ http://aquarius.ime.eb.br/ webde2/prof/vania/pubs/2011/ANTP_2011.pdf>. Acesso em: 09 jun. 2016.

PORTUGUAL, L.S.; GOLDNER, L. G. Estudo de Polos Geradores de Tráfego e de seus Impactos nos Sistemas Viários e de Transportes, 2003. Editora Edgard Blücher.

PREFEITURA DA CIDADE DE SÃO PAULO. Ciclovias - Utopia ou Realidade. Transporte Sustentável. Secretaria de Relações Internacionais, 2006. Disponível em: < http://www.aulasaopaulo.sp.gov.br/transportesustentavel3.htm>. Acesso em: 17 mar. 2017.

PREFEITURA MUNICIPAL DE NITERÓI. Apoio à Revisão do Plano Diretor Municipal de Desenvolvimento Urbano (PDDU) do Município de Niterói. Produto 7 - Diagnóstico Técnico, 13 ago. 2015.

ROSENBERG ASSOCIADOS. O uso da bicicleta no Brasil: qual o melhor modelo de incentivo, 2015. Disponível em: <http://www.abraciclo.com.br/downloads/34seguranca/968-estudo-rosenberg>. Acesso em 14 de mar. 2017.

RELIANCE FOUNDRY. Bike Culture: Europe vs. America, 2015. Disponível em: <http://www.reliance-foundry.com/blog/biking-usa-europe\#gref $>$. Acesso em: $11 \mathrm{abr}$. 2017.

Recebido em: 20/01/2022

Aprovado em: 21/02/2022

Publicado em: 24/02/2022 